\title{
Temporarily Abled: How Exoskeleton Experience Reinvents Bodies in Spinal Cord Injury and Cerebrovascular Accidents
}

\author{
Denisa Butnaru
}

Received: 29 May 2020 / Accepted: 9 November 2021 / Published online: 30 December 2021

(C) The Author(s) 2021

\begin{abstract}
Recent achievements in rehabilitative robotics modify essential parameters of the human body, such as motility. Exoskeletons used for persons with neurological impairments like spinal cord injury and stroke enter this category by rehabilitating and assisting damaged motor patterns, achievements thought impossible until not long ago. Unlike other examples leading to similar dysfunctions, such as diseases or tumors, the experience of an accident causing a spinal cord injury or the occurrence of a cerebrovascular accident is sudden and perceived as a radical event. This often leads to deep consequences for one's own body capacities. Exoskeletons attempt to alter this condition, contributing to forge a temporary abled body, although this currently happens in the restricted space of a clinic or a lab and under very controlled conditions for the predominance of users. Using qualitative empirical material from an ongoing study in sociology, including expert and narrative interviews as well as ethnographic visits in labs and centers that design and test exoskeletons, this article addresses the challenges and gains that people with stroke and spinal cord injury experience during their training with exoskeletons. The discussed cases contribute to reassess categories from the phenomenological paradigm, disability studies,
\end{abstract}

D. Butnaru $(\bowtie)$

Lehrstuhl für allgemeine Soziologie und Kultursoziologie, Universität Konstanz, Fach 41, 78457 Konstanz, Germany e-mail: denibutnaru@gmail.com and the role medical technologies play in contemporary body worlds.

Keywords Exoskeleton - Spinal cord injury · Cerebrovascular accident · Phenomenology · Temporary abled body

\section{Introduction}

Exoskeletal devices have steadily nourished their own field of imagination. Due to the advent and proliferation of science fiction movies, their popularity has increased, influencing their conception in terms of augmentative technologies. Currently, exoskeletons are used in three applied fields: rehabilitation, industry (automotive and logistics), and military. Whereas in the first field, in which exoskeletons accompany impaired bodies contributing either to assistance to their damaged functions or rehabilitation of residual functions after neurological injuries, exoskeletons accompany able bodies in the two other fields where they are implemented. Here, they provide specific assistance for definite tasks. All these scenarios initiate questions about how corporeal boundaries in the form of abilities and capacities are temporarily modified. Exoskeletons also challenge the understanding of some forms of disability. If the cyborg and the prosthetic are already well known cultural tropes that redefine the boundaries of the body [1-3], with the advent of such technologies as exoskeletal devices, 
the association between the human body and technological parts reaches a deeper level, where the categories of capability and ability are negotiated anew. Their implementation has crucial consequences in that they challenge some forms of impairments, among which some were thought to lead to irreversible bodily states. Examples such as spinal cord injury and stroke are relevant in this regard.

The aim of this paper is to show what role exoskeletons play in rehabilitation and their impact on forms of bodily ability while analyzing two categories of impairments: spinal cord injuries and cerebrovascular accidents, which are more commonly known as stroke. These examples shall be theoretically correlated to the conceptual background of the phenomenology of the body. The reason why the phenomenology of the body provides an important categorical instrumentarium to observe the changes lived by users of these devices is that the target parameter modified by exoskeletons is impaired motility, which for the limited period of the device's use is adjusted into a form of ability. In this sense, exoskeletons play a crucial role in the production of what I name a temporarily abled body, a concept I intend to discuss in the following sections. To do so, I will mobilize empirical qualitative material in the form of narrative and expert interviews from a research project in sociology conducted between 2014 and 2021. The overall material is also comprised of ethnographic field notes from multi-sited ethnographic visits in laboratories and centers in three countries (France, Germany, and Switzerland). This analysis reassesses notions from the field of disability studies while relating them to new forms of medical technomaterialism and their correlated phenomenologies.

My intention is to document how exoskeletons open new spaces of corporeal ability while drawing on the aforementioned impairment examples and therefore to show their potential for deeper understandings of bodily boundaries and conceptualizations of disability inspired by categories rooted in the phenomenological tradition. Because they invent new forms of perceiving and living corporeality as well as perceiving and using a special form of technological object, exoskeletons have a clear impact on subjective forms of experience. Due to their externality to the human body-they are literally attached to it-they influence the perception and material production of impairment; hence, their role in forging conceptions of temporary ability that are contextually defined and related is crucial.
After generally describing how bodies and machines interrelate and how exoskeletons contribute to this wider history of material coproduction, I will further discuss some contemporary concepts from the phenomenology of illness [4-6], then from phenomenological studies analyzing motility and agency [7-11], and highlight how some of these contribute to the understanding of the temporary ability production with exoskeletons. My tendency to favor the phenomenological background is justified by the fact that this tradition allows a clearer focus on how the subjective body of the impaired person using the exoskeleton transforms during the use of the device, and on what concrete challenges are faced - and also newly permits a reflection on how specific forms of living one's impairment are impacted by these novel technologies. My argument that temporary forms of corporeal ability emerge during the process of using the exoskeleton will be correlated to disputing the common view associating exoskeletons with enhancement technologies. I will support my arguments with excerpts from empirical qualitative material.

\section{Bodies and Machines: Some Pathways in Technological Medicine}

There is no doubt that the fascination for machines has been a constant in the cultural history of mankind $[12,13]$. Especially during the Enlightenment, this development knew a particular attention. Indeed, notable automata were imagined in this period and counted among the epoch's wonders. They were heralds 'of the modern, industrial machine age, an age in which the economic, social, cultural, and aesthetic constitution of humans changed fundamentally and supposedly became "mechanized" (see p. 2 in [14]). Yet, the existence of specific technological objects related to the history of medicine belongs to other forms of imagining human bodies than those which sought their simulation. The growing development of 'technological medicine' [15] in the past few decades raised particular questions about the role of 'medicalization' [16-18]. 'Medicalization' is a phenomenon that marks an obvious shift in the definition and role of medical sciences, impacting what is understood as health, illness, disease, or impairment, and on another level, questioning contemporary perspectives that permit the manufacture of life. However, if some 
medical treatments or forms of medical intervention inside human bodies may remain unnoticed [19], situations where deficiencies and impairments are accompanied by visible gadgets directly influence the perception of the human body, as well as that of the impairment that individualizes this very body as such. This latter aspect characterizes exoskeletal devices. One of the aims of their intervention is to encourage thinking of 'dis/ability as a mode of inclusion that does not exclude but includes the heterogeneity and difference of the other' (see p. 98 in [20]).

The intervention of medical technologies and their correlated possibilities of corporeal extensiveness further reoriented the question of how we consider bodies accompanied by machines in these particular contexts and how such interventions reformulate abilities and capability repertoires understood to be damaged; en gros, an inquiry into exoskeletons contributes to portray how bodies accompanied by these technologies attempt to do what they can do while being with these specific devices. In sociological body studies, as well as in more theoretical ones inspired by phenomenology and psychoanalysis [21, 22], a primary object for analysis have been prostheses. Their semiotic potential allowed them to cross a variety of boundaries, especially from a technological imaginary towards a cultural one (see p. 2 in [23]). Although conceived in terms of machines only recently, ${ }^{1}$ by which I mean objects with forms of agency autonomy, prostheses have a much longer history with and about impaired bodies. The needs for their development increased especially due to military conflicts $[24,25]$. After the First World War, the development of prosthetics had a crucial role in reassigning a civilian professional identity $[26,27]$ to injured men, thus ensuring their reentry into the workforce. The current field of prostheses has changed. In addition to injuries resulting from military conflicts, diseases such as diabetes that often lead to

\footnotetext{
${ }^{1}$ I particularly refer to bionic prostheses, which were developed in the past years and which may be connected to apps on a smartphone that allow their users a variety of motility repertoires, some of which may not be anatomically allowed by the human hand or arm. One of these, for example, is the rotation of one's hand at $360^{\circ}$. For concrete examples of projects in this field, and the companies developing them currently, see the website of Cybathlon 2020 organized by ETH Zürich, where both powered-arm as well as powered-leg prostheses were presented and were used by impaired persons in a race. https:// cybathlon.ethz.ch/en/projects-events/cybathlon-2020/results (accessed 15. 04. 2021)
}

amputation of limbs, or the growing number of accidents due to traffic or incidents at work, completed the range of acts transforming human bodies into human bodies with missing parts. The obvious consequence of such changes is that prostheses have become increasingly widespread. Through this development, they have also redefined the imaginary of disability, forging new conceptions of bodily in/capacities, but also on a more general level, of human life and its material boundaries. During these semiotic and practice-oriented shifts, prostheses affirm 'their status both as novelties and as less spectacular objects of everyday use' (see p. 438 in [28]). Their democratization during the past few decades and their growing visibility led to such a transition with obvious impacts on their understanding in terms of 'medical technologies.'

Exoskeletons, however, belong to another category of technologies. They also hold a special place in the more general understanding of prosthetic devices, if one is to assign them to this socio-technical category. Unlike prostheses, which mostly 'replace' or 'fill in' missing body parts, exoskeletons have the special function of completing, adjusting, or assisting [29, 30] abilities of human bodies. They do not relate to missing body parts but, as far as their medical use is concerned, to dysfunctional bodily capabilities or abilities. Furthermore, exoskeletons display a specific external relation to the body, imposing an explicit distance that differs from prostheses perception. Notably, prostheses are often conceived as belonging to the human body, despite there being a separate object which replaces a limb, a function, or part of an organ, as in the example of retinal prostheses.

Robotic exoskeletons, originally called 'extenders' [31], are used as assistive and rehabilitative devices for persons with stroke and spinal cord injury and are 'defined as a class of robots that extends the strength of the human hand [author's note: or the leg] beyond its natural ability while maintaining human control of the robot. A specific and singular aspect of extenders is that the exoskeleton structure maps on to the human actor's anatomy' (see p. 8 in [32]). More concretely, they influence some of the body's range of movements, and consequently, what an impaired person can do in terms of both motility as well as sequential agency. From this point of view, exoskeletons are devices which explicitly impact phenomenological levels of 'I can' [9]. Nevertheless, if technological devices and more specifically medical technologies 
are generally conceived to modify, alter, and possibly ameliorate human capabilities, there is a difference of use between medical prostheses and exoskeletons. Unlike prostheses, exoskeletons are designed not only for persons with impairments. They may be used by persons who have 'missing' functions in their bodies, such as neurological impairments, or by healthy persons who require assistance to perform certain tasks, mainly in paid labor environments ${ }^{2}$ [33].

If it is true, as Daniel Black notes, that 'the interplay between our understanding of machines and the human body can be seen to extend much further than simply desiring machines that simulate our own form and movement' (see p. 38 in [34]), the development and use of exoskeletons take this idea a step further in that what exoskeletons really transform are capability forms of the body and specific bodily impairments that were thought to be irreversible not long ago. In this sense, the result of their application is not only 'a reshaping of the environment to complement the human body' (see p. 38 in [34]), but a reshaping of fundamental functions of the body, and with these, a reshaping of dis/ability perceptions and their contextual and cultural meanings. From this point of view, exoskeletons are in no way neutral technologies. Quite the contrary: through their focused application, they influence the human being's awareness, one's proprioception, and thus one's literal feeling of being able to move when motility functions are deeply altered. In this regard, exoskeletons hold a special role. Unlike other medical technologies or technologies tout court, exoskeletons influence how we are our bodies in very specific environments and contexts. By this, I mean that they impact a very subjective parameter: our motility repertoire, and its correlated form of intentionality, which is motor intentionality (see p. 112 in [35]). This deep change that they produce is especially observable in rehabilitation environments. Here, exoskeletons represent an obvious medical technological revolution. What they produce in rehabilitative environments consists of their temporarily adjusting motor impairment forms. At first sight, this technological redefinition of impairment may seem of little importance. And yet, as my fieldwork data show, for people who have spent

\footnotetext{
${ }^{2}$ I understand work in industrial environments as well as activities carried out by armed forces as 'paid labor.'.
}

several years using a wheelchair after an accident leading to spinal cord injury, verticalization with an exoskeleton does not only reinvest an impaired body; rather, the result is of a high phenomenological envergure because what is impacted is one's phenomenological 'own body.' Exoskeletons modify one's 'what it is like' to experience a temporary form of ability.

Although mostly used in a specific location (that of a clinic or lab) and for a limited period of time (the length of a therapy session), exoskeletons change strongly impaired bodies into bodies that regain a few moments of ability. To put it differently, what exoskeletons do to the body is to 'recorporalize' it $^{3}$ and thus impact how it is lived. Contrary to a widespread idea in sociological theory, encouraged by the Marxist tradition that broadly associates machines and technologies with the concept of alienation [37], the current developments in the medical field aim precisely at creating nearness to technological devices. Here, parameters seeking similarity to and the simulation of the various functions of our bodies are central. What these medical technologies create, besides medical value for the very specific field of application for which they were designed, is corporeal value. They allow human bodies to be reinvested, and in so doing, they temporarily change the balance between ability and impairment.

Neurological deficits in the human body, the very example evoked below in this paper, make it possible to invent the body anew by allowing artificial means to intervene into one's anatomy. In my position, intervention does not argue in favor of the 'cyborg' image. This is justified in particular by the fact that the materiality of the machine very often challenges the materiality of the human body; communication between the two is not always successful. However, the efficacious cooperation between impaired bodies and medical technologies redimensions perceptions and feelings of impairment. Being visible, exoskeletons operate a direct shift from an impaired body to an able one; if arm and leg prostheses, pacemakers, and various implants (cochlear and retinal implants are

\footnotetext{
$\overline{3}$ I use the term 're-corporalize' as an antonym of 'decorporalize,' a term mentioned by Jonathan Crary [36] with respect to the use of camera obscura in the Renaissance. In this context, Crary states that one of the functions of the camera was to 'decorporalize vision,' 'to sunder the act of seeing from the physical body of the observer' ([36], p. 22).
} 
now starting to be well known, for instance) [38] have been operating inside the human body, exoskeletons surprise by their externality and exteriority. In such a position, they claim a clear displacement of 'agency from human to artifact' (see p. 24 in [3]) whereas they clearly advance new conceptions of how users and their impaired bodies are circumstantially produced [39].

\section{Why Exoskeletons Reinvest Phenomenological Conceptions of the Body}

Generally, technologies change the way we feel and are our bodies, and exoskeletons are one example among many. They engage us in what Lambros Malafouris calls 'an extended intentional state' (see p. 176 in [40]): as soon as we are accompanied by technological devices, we do not think about them; rather, as Malafouris argues, we tend to think through and with them (see p. 176 in [40]). Some devices, though, may be more challenging in this respect, both in the efforts, they require from their users as well as from the point of view of the impact they produce. The use of exoskeletons for rehabilitation purposes reflects the second situation more, for what these devices induce in the bodies of the impaired persons are strong experiential modifications.

Motility impairments are a special case where technologies intervene. They draw attention in a more direct manner to the loss of transparency that usually characterizes our bodies and which is often also visibly marked. As Havi Carel notes, 'the healthy body is transparent, or absent, and illness is the loss of this transparency' (see p. 8 in [5]). Not being able to walk, move one's arms and fingers, or feel one's limbs is a very challenging experience that strongly recalls the centrality of our bodies. Exoskeletons therefore interfere in repertoires of both not being able to move and into forms of not being able to feel one's body. They reformulate sensorimotor qualities, and in so doing, they redistribute subjective qualities of impaired users they accompany.

It is widely acknowledged in the phenomenological paradigm that the body holds a fundamental role. Starting with the initial Husserlian position, which first discussed the body as a primary source of experience, up to the phenomenology developed by Maurice Merleau-Ponty, the body has been a constant topic of inquiry. Whereas in Edmund Husserl's perspective, the body qua lived body (Leib) is considered to be the zero point of any experience [41], the MerleauPontyan perspective deepens this understanding.

One of the functions of the body central for theconstitution and sense-making of experience is, according to Merleau-Ponty, proprioceptionor kinesthetic function. In the Merleau-Pontyan vocabulary this function wasnamed 'body schema' (see p. 100-105 in [35]). The body schema is necessary for our experience of objects in general, and in particular for our capacity to embodythings and objects. The cases discussed by Merleau-Ponty to exemplifyembodiment of objects, which are often quoted in later studies discussing notionsfrom the phenomenological background [40], refer to the hat worn by a woman andto the cane of a blind person. His theorizing thus provides a categorical basisfor more detailed and complex cases evoked in contemporary studies inphenomenology, more explicitly in enactivism [7, 8, 42, 44]. In this newlydeveloped philosophical branch, one of the defended central views based on theclassical perspectives in phenomenology, is that doing and action are central. AsShaun Gallagher, one of the main figures of this current orientation inphenomenology, notes when discussing the constitution of cognition in theenactivist view, 'the body's influence on cognition is, at least, threedimensional, including the influence of sensori-motor contingencies, affectivefactors, and intersubjective processes' (see p. 42 in [8]). The presence of objects,and explicitly of technological objects, is an invitation in terms of what 'Ican do with them'. These capacities are deeply affected in cases of spinal cordinjury and stroke, and exoskeletons attempt to recapture damaged and sometimeslost motor patterns. In this attempt, what they seek to restore ventures beyondanatomical properties such as walking into forms of what 'I can do with objects'.The latter aspect may be more frequent in cases of stroke, where only half ofthe body is afflicted by the injury in the brain.

Focus has also been placed on the role of proprioception in some recent studies in phenomenology analyzing cases of impairments related to motility dysfunctions, in which one of the analyzed examples was the locked-in syndrome [42, 43]. However, since in rehabilitative robotics many projects are works in progress, the phenomenological impact of 
exoskeletons as developing technologies has not been assessed. This article intends to provide the first contribution in this direction.

In sometimes relying on phenomenological presuppositions, some defenders of the enactivist paradigm argue, for instance, that proprioception has a crucial role in the genesis of perception [44]. This implies that changes in kinesthetic functions affect perception and thus our capacities of sense-making, having fundamental consequences for the conception of the 'body schema,' which is highly impacted in neurological affections. At a subjective level, the proper functioning of the body schema influences the structuring of subjective experience and plays a crucial role in our configurations of meaning. The body schema is also vital in establishing interaction possibilities with the surrounding world, as well as with other fellow humans, making it possible to further understand the embodied subject in terms of a 'body-in-action,' as some contemporary views relying on the phenomenological tradition argue (see p. 531 in [42]). It is this 'body-in-action' that is strongly challenged in neurological impairments, and this is what exoskeletons attempt to transform. In so doing, what they actually alter are, along with the anatomy of bodies, the very lives of their users. In view of such transformations, I understand exoskeletons to be 'corporeal manufacturers' and assign them a crucial role in the wider history of medical technologies [45-47] that eventually produce novel life forms while attempting to heal.

\section{Spinal Cord Injury and Stroke: Phenomenological Forms of Bodily 'Otherness'}

Experiences of spinal cord injury and stroke are phenomenologically relevant because they are usually lived as radical events, and it is these sudden corporeal changes that exoskeletons seek to rehabilitate or assist. As a consequence, not only are exoskeletons as technologies of health engaged in the normalization and 'ordering of disability' (see p. 375 in [48]); additionally, they order one's own experientiality. They intervene in the very subjective details of how people have experienced motor impairments living in their own bodies.

Generally, illness or disease exposes us to forms of alienation, or to a sort of "bodily "otherness," as Fredrik Svenaeus calls this type of experiential transformation (see p. 37 in [49]). In the perspective of Svenaeus, alienation concerns the 'issue of living with a body that is no longer only one's own but also other to its owner in some way. When the body reveals such a life of its own, this is, in many cases, an alienating and also an uncanny experience for the person to whom the body belongs' (see p. 37 in [49]). Obviously, when one experiences an accident leading to paralysis, this is very different from experiencing a case of influenza or occasional pains in one's body. Spinal cord injury affects the nerves in the spinal cord, whereas a cerebrovascular accident involves oxygen-rich blood flows being blocked in some portion of the brain. Without oxygen, the brain cells may be damaged or die, which further leads to various troubles in those parts of the body controlled by the affected brain cells. These corporeal changes are radical states, turning the present body into a body foreign to oneself. If the body is our primary 'being-athome,' in cases of spinal cord injury or stroke, one is confronted with a form of un-home-likeness or of a 'not-being-at-home' [50, 51].

I find the concept of alienation helpful to describe in the first place the changes occurring in the transformed corporeal capabilities and abilities of the impaired persons. Like many changes in the body, the alienation stage may be associated with the discovery of the sudden bodily modification the impaired persons experience when they realize forms of inability such as not being able to walk, move their legs and hands, or articulate speech the way they used to before they lived the event leading to their impairments. In a further step, this 'otherness' caused by neurological damage starts to be gradually transformed into everydayness and assimilated into a new form of habitual body. Exoskeletons interfere in this 'alienated' body characterized by corporeal dysfunctions, thereby causing a second form of alienation that is technologically induced.

From a phenomenological point of view, one may describe such type of experiences in terms of a 'corporeal event' where the character is marked by a specific temporal exceptionality. An event is an exception, a situation that reinforces the character of becoming an 'other' body and hence of being alienated. The occurrence of injuries such as those of the spinal cord or of lesions in the brain leading to a stroke institutes a biographical bifurcation that 
is bodily inscribed. This bifurcation becomes a part of the body's motility repertoire, and it is an obvious visible mark of corporeal alienation, if one stays with the aforementioned perspective of Svenaeus. The opposition between a former body that was healthy and represented a 'primary being-at-home' (see p. 25 in [49]), and a present impaired body is wellknown in the field of disability studies. One of the most detailed accounts describing this opposition is that of Robert Murphy, who became a tetraplegic, in his The Body Silent. Murphy notes that the 'before' and the corporeal 'after' of his condition are defined in contrasting terms: 'just as my former sense of embodiment remained taken for granted, positive, and unconscious, my sense of disembodiment is problematic, negative, and conscious. My identity has lost its stable moorings and has become contingent on a physical flaw' (see p. 105 in [52]).

It is necessary to mention though that every spinal cord injury and stroke experience are different, implying that every experiential form of alienation and 'otherness' in one's own body varies from one person to another. Thus, processes of learning one's new body are not interchangeable. In these oscillations in which exoskeletons actively interfere and sometimes correct corporeal disability appears 'as a breakdown of [this] normal order of the body, undermining the capability to act' (see p. 383 in [48]). One of the interviewees, Christian, who has lived for many years with a spinal cord injury paralyzing his legs, describes how he discovered his new body limits in the following terms:

It was really very, very difficult, I must say. One realizes all of a sudden that one is paralyzed, and that one can never walk again. And, yes, this was in itself the first reason where one feels that one's world fell apart. Because ... why? I was so young. I could still do so much. And my wife was pregnant then [at the time of the accident]. And, how should it go further? And then, first, one had to hear one's own thoughts. And then further on, one had to start fighting.

One can notice, something like after twelve days of being in coma that the muscles are completely weak. You cannot hold a fork. You have to learn everything. First, I was fed, and then I had to do it by myself. I had to learn it with a lot of training. To hold a fork and bring it to the mouth. And this was then very, very difficult' (Narrative interview, Germany, my transl. from German).

The 'other' body acknowledged in the stroke experience is portrayed alongside a description of selfdiscovery that is similar to the description provided by Christian regarding his primary consideration of having a spinal cord injury and being hospitalized. In both types of neurological impairments, this first reference remains a space of learning corporeal habits that characterize able persons. Thomas, a former sports teacher, who experienced a stroke after being retired, described the following to me:

Denisa: 'And what did you concretely do (in the clinic)?'

Thomas: 'Yes, what they (the staff in the clinic) practiced with me was standing up. But they did it with a machine. So, I was put in this machine which I called the 'standing gadget' and I had to shave myself while standing up or eat breakfast while standing up' (Narrative interview, Germany, my transl. from German).

David, who has a spinal cord injury, evokes a perspective similar to Thomas. One discovers what one still can in order to further reinvent one's 'own body' with an exoskeleton and where certain type of motor exercises are experimented to precisely chart residual functions. He said:

'On the second day I arrived, they put me in a wheelchair. I collapsed straight away (laughs). That was fun. Your body is not used to it anymore. So, when they put you in an upright position your circulatory system breaks down. [...] A day later it was okay, but your body needs to adjust for these kind of things. And then, they put me in a wheelchair. But I wasn't allowed to do much yet. The beginning was all start off. Just learning how to transfer, how to get from a bed into a wheelchair or how to get from a wheelchair into a bathroom, onto a sofa, onto ... how do you go over a little step. All that kind of stuff. Learning how to deal with a wheelchair [...] So, after that, I started training on walking again. This included training with exoskeletons from [firma X] and walking with braces' (Nar- 
rative interview conducted in English, Switzerland)

The preliminary 'exercises' in the clinic represent an important corporeal marker. What they initially point out is the separation between an external world of the abled from that of the impaired, and second, the separation between two bodies belonging to, or rather being the same person. Exoskeletons aim to modify the experiential boundaries between these worlds. In the process of acquiring motor habits that belong to one's everyday life and seem to be new due to the blockage caused by the injury, the phenomenological negotiation between ability and in/ ability reaches new stages. Interestingly, although these motor habits used to belong to the corporeal repertoire of the impaired person before the injury occurred, they need to be produced anew. The source of collaboration between the impaired person and the exoskeleton is grounded within this corporeal dissymmetry, confronting past healthy forms of one's self to present impaired ones. In this vein, one may agree with Katherine Ott, who affirms that 'artifacts actively shape and define disability' (see p. 119 in [53]), and I would add, the very phenomenologies of in/ability that they sequentially produce. The technocorporeal resources and materialities activated by these novel devices bring forth further lines of thinking about corporeality and its specific forms of in/ ability management. In so doing, they emphasize the production of what I name the 'temporary abled body,' which is what I will discuss in the following sections. This category fosters further understandings of how corporeal in/ability is characterized by continuity and discontinuity, and how such experiential shifts contribute to shape novel manners of comprehending contemporary cultures of body boundaries manufacturing and, at a larger scale, levels of life and live-ability with motor dis/abilities.

\section{Attempting to Produce Intimacy with Machines: How Exoskeletons Reinvest Phenomenological Forms of 'I can'}

As mentioned above, exoskeletons are technological objects primarily influencing the ability to walk or the movement of the arm or hand, a trait closely associating them with the evoked phenomenological category of 'I can.' The category of 'I can' characterizes not only the classical Husserlian conception of subjective consciousness in phenomenology but also identifies the human body as a sum of doing and acting possibilities. Interfering into this experiential background renders exoskeletons intimate technologies. The type of intimacy they sequentially produce, however, is of a different nature than, for example, implants, transplants, or even prostheses. Since exoskeletons literally represent an addendum to the biological body, they may mostly inspire distance instead of intimacy. As such, they share a common characteristic with prostheses that refers to the property of a medical technology to own a 'temporal trajectory,' as Dalibert and Goffette [54] explain. In the view of these authors who discuss prostheses, these technologies may be detached from the human body, and so may be exoskeletons. If one stays with Dalibert and Goffette's definition of prosthesis, this is understood as responding to a missing organ or limb. Because they do not replace limbs, exoskeletons belong to the category of orthoses. Furthermore, the absence of exoskeletons does not endanger the life of their users, as it is for example the case of a pacemaker [55] or insulin pumps [56], both indispensable for their users to go on living.

However, the fact that exoskeletons interfere into parameters characterizing motor intentionality grants them a specific form of 'nearness' to the human bodies they accompany. When experiencing an impairment, the concerned person is identified as ' $\mathrm{I}$ no longer can' (see p. 81 in [57]), acknowledging not only a functional counter-model of one's own body but also a practical-contextual one. Yet, in the observed cases of spinal cord injury and stroke, this 'I no longer can' may be adjusted according to residual functions that the impaired people still have; it is this motility stock that exoskeletons reorganize while favoring the performance of nearly healthy types of kinetic patterns. In this process of learning, new aspects of 'praktognosia,' namely our 'manner of reaching the world and the object' (see p. 141 in [35]), are negotiated.

People with spinal cord injury and experiences of stroke often develop new models of dealing with their new condition and thus readjust their 'I can.' One example evoked by experts in the field is that, when the healthy motor pattern cannot be mobilized to perform a gesture or a simple form of action, impaired persons make compensation movements. Translated into a more recent phenomenological vocabulary associated with the work of Drew Leder [57], this 
bodily change describes one possibility in which the 'I cannot' aspect in the body tries to recuperate functions of a former 'I can.' In this process, exoskeletons help in bringing back a correct movement that the concerned person used to be able to perform. As one of the experts explained to me in an interview, some people who experienced a stroke may try to move their arms. The motor intention exists, yet since the brain cannot recuperate the correct path to help perform the intended movement pattern, the result is a biased movement. Hence, the compensation movements develop. He said:

'For instance, this [other] patient [with CVA], who thought that he couldn't make the movement in a different manner than via his shoulder ... he just couldn't imagine that he could do it differently. He didn't believe it. He had to watch himself in the video in which he was moving. He watched himself many times when he was moving his arm with the exoskeleton, I mean, when he was performing the proper movement. [...] He just couldn't imagine that he could move his arm in another way than with the compensation movement via his shoulder' (Expert interview, Germany, my transl.).

The experience of spinal cord injury differs qualitatively from forms of motility deficiency resulting from a stroke because the connection between the nerves in the spinal cord cannot be reestablished (at least not current-state exoskeletons). For some cases of stroke, physiotherapy and robotic therapy with the exoskeleton may be successful in reestablishing some of the former motility functions of the body. The corporeal habitus of the impaired persons with spinal cord injury is hence radically challenged by the use of the machine. It is this unprecedented change which raises additional questions not only phenomenologically, but for the broader field of disability studies as well. If the relation between the 'I can' and 'I cannot' is already recalibrated by the emergence of the motility deficiency, the rehabilitative device produces a new corporeal field: that of a temporarily abled body. This new form of corporeality is based on a process of learning new body habits with the exoskeleton and correlatively forms of practice, although these achievements are delimited by the time of use of the device as well as by the location, which is usually that of a specific institution (a clinic or sometimes a lab).
Under these conditions, motor pattern achievement and, therefore, visible progress in transforming chronical conditions of corporeal disability into ability remain relatively fragile. Intimacy with exoskeletons is the main aim; yet, as the observed facts show, this is rarely achieved and is the case for only a certain type of users. Consequently, corporeal motor abilities acquired in clinics or labs may contest limitations produced by impairments such as spinal cord injury or stroke, affirming the position of exoskeletal devices as extensions of bodily competence. However, such achievements do not characterize the majority of users. People who manage to recuperate motor functions are predominantly young people who often used to practice sports. As one of the interviewed persons, himself having a spinal cord injury and being an active exoskeleton user, described these preconditions for the device's use, 'first of all, one needs to be a young person, who is available, dynamic and in good health. This means that one shouldn't have any complications, scars, or other problems. So it's a profile chosen according to specific criteria, which means that the exoskeleton is not for everybody' (Oliver, France, my transl. from French). His perspective mirrors that of a physiotherapist, who noted the following:

'That is why, ideally the target is a young population, people who have not been in a wheelchair for a long time, and who did not develop bad habits. Because one may develop many bad habits after a few years in a wheelchair. For example, bones become stiff, one may have no movement possibility or be constantly laying down. So, there are some persons for who verticalization is impossible. And thus, there are incompatibilities' (Physiotherapist, France, my transl. from French).

Accordingly, what is prevalent before engaging in any form of working with an exoskeleton is the assessment of what one's own body still can. As Thomas Droulez argues, "what is at stake here is the kind of meaning that the subject grants to her 'self' (à son moi) [...]. Of course, this involves first a self-awareness as being the agent of voluntary actions, being the subject of one's own thoughts and the owner of one's body' (see p. 228 in [58], my transl. from French). It is this awareness which changes due to the experience of impairments and 
to learning one's body while working with exoskeletal devices.

Consequently, phenomenological categories such as 'I can' and 'I no longer can' are redefined, impacting the awareness of one's own sense of agency, but also correlatively one's sense of self-ownership, the latter referring to 'the prereflective experience that I am the one who is moving or undergoing an experience' (see p. 132 in [7]). If the relation between the embodied self and the surrounding environment is usually unmediated (in that I am the one who directly experiences the objects around and who interacts with other human fellows), exoskeletons introduce an experiential 'in-between,' the decision to move being partly delegated to the device. It is because of the intentionality distribution that one may theorize a specific intimacy, a form of co-working and co-production of the users' temporarily abled body, yet as the previous interview excerpts clearly show, this remains highly specific to individual bodies and impairment degrees. Indeed, exoskeletons establish 'new kinetic normativities' (see p. 10 in [59]), which may gradually develop into motility patterns closer to what healthy bodies can. Thereby they concretely change one's 'sense of agency' (see p. 132 in [7]) and hence contribute to the emergence of temporary forms of ability. In so doing, one may argue that these technologies circumstantially recover forms of life.

\section{Exoskeletons and Their Temporary Abled Bodies}

According to Fiona Campbell, a scholar well-known in disability studies for theorizing 'ableism' [60, 61], “'ability' employs a judgment that establishes standards of body and mind that are actionable in the present or in projected futures' (see p. 46 in [62]). As I showed in the previous sections, exoskeletons first interfere in personal histories in which 'own bodies,' once identified as able, have become impaired and, further on, after the impairment occurred, into people's remaining kinetic repertoires. If one retains Campbell's idea regarding standards of the body (and mind) $)^{4}$ in processes of reappropriation with an exoskeleton, standardization is usually directed towards

\footnotetext{
${ }^{4}$ I do not operate with the Cartesian distinction between 'body' and 'mind.' In current phenomenological approaches, the mind is conceived as embodied [7, 8, 63], and this is the position I endorse.
}

managing 'the unmanageable' (see p. 125 in [53]). With respect to my case studies, this trait refers to the limitations and unpredictability of corporeal reactions that users of exoskeletal devices may experience. In this line of thought, to appropriate one's body while working with an exoskeleton means first understanding the corporeal limits and possibilities of that impaired body.

An important categorical distinction made by Havi Carel in a study on the phenomenology of illness, which is pertinent to my own argument, refers to a form of 'active' body and a form of 'passive' body (see p. 32 in [5]) that generally characterizes how our corporeality functions. Human bodies, regardless of their being able or impaired, are all active (through intentionally sensing and recording events or aiming at doing activities) and passive. This latter feature refers to various anatomical processes happening inside us and of which we are not necessarily aware. The work of appropriating one's body with an exoskeleton challenges the distribution between passivity and activity in the sense that levels of awareness shift; activity may sink or transform, and so does passivity. This significantly results in modifications of proprioception. As Merleau-Ponty notes, 'a movement is learned when the body has understood it, that is, when it has incorporated it into its world, and to move one's body is to aim at the things through it [...]' (see p. 140 in [35]). Our embodied relationships shape the way we experience ourselves and our possibilities to act. The current novelty of what exoskeletons do is their accompanying of human bodies thought to be irremediably impaired in discovering motor resources anew; thus, they actively modify the embodiment relationships of their users, operating a transfer from in/ability to temporary ability. This process urges impaired persons like those who have experienced spinal cord injury or a stroke to develop new reflexive levels. Due to sustained reflexive engagement of the impaired people, processes of appropriation take place, further contributing to shape what I call a temporary abled body.

Besides a strong conscious focus from the impaired person, which is almost the opposite of what happens when we are proprioceptively engaged with other objects or tools when our bodies function correctly $[7,8]$, the gradual manufacture of a temporary able body is also related to the presence and competence of experts. Engineers and medical doctors play a decisive role but it is 
physiotherapists who work the most closely with users to achieve partial recuperation or preservation of motor patterns. Thus their role is crucial in terms of how bodies are able to perform following spinal cord damage or stroke. One of the reasons for their indispensability in the production of temporary forms of ability with exoskeletons is that physiotherapists objectify essential details about how impaired bodies change.

One of the physiotherapists explained in an interview:

'There are some criteria regarding how one learns to work with an exoskeleton. For instance, after three months of practice one should be able to walk ten meters without any help; or one should be able to stop the machine alone, or that one should turn around with the machine alone, change without any help the various functions of the exoskeleton, such as sitting down or standing up, or that one gets in and out of the exoskeleton on himself. One should show the person that she can do that. Usually one manages this. [...] But you cannot say this person is good at it or this person is not. Everything can happen. For instance, even persons who were in the wheelchair for twenty years, if they have physiotherapy regularly, then they learn to work with the machine relatively quickly' (Physiotherapist, Germany, my transl. from German).

As with other activities requiring skilled movement performances and sometimes involving the use or interaction with objects, such as the practice of sports or playing music, the interaction with an exoskeleton is demarcated by an interval of time. This may relate to standing up, walking, or exercising movements one uses in everyday activities, all movement patterns we mostly understand as 'natural.' As Black pertinently evokes, 'devices do not themselves create new sensory experiences - only living bodies can do that' (see p. 53 in [34]). Yet what some devices in rehabilitation environments do, including exoskeletons, is to reassign capabilities to some living bodies that live with restricted kinetic repertoires. In doing so, they intrinsically contribute to appropriate former forms of selves along with former bodies while simultaneously engaging the user in experiential negotiations.
Exoskeletons are devices offering the possibility to experience new forms of living with impairments, but also of what it is to produce ability and new forms of corporeality, albeit very contextually and under controlled conditions. Contrary to images and articles in the media portraying exoskeletons along with prostheses as enhancement technologies, they are a far cry from contributing to augmentation. Especially in the example of rehabilitation, the explicit target for the development and implementation of these medical technologies is to accompany people having motility dysfunctions in better living with their bodies, and not to transform them into science fiction superheroes. Currently, the proper use of such technologies remains a very challenging process, often relying on restrictions that are imposed by the body of the patient herself or himself, as I have formerly explained. The many stages involved in building trust in the tool (see p. 213 in [64]) are connected, I claim, to sustained practice and the development of corporeal know-how to which specific body techniques are associated. These need constant actualization and maintenance. As Robert Riener, an expert in robotics, explained in a presentation made in 2017 at Universitätsklinikum Freiburg,

'the longer you train, the faster you move, the more repetitions you can do. And this number of repetitions is an important variable or parameter in the gait training, or in physiotherapeutic training in general. But that's not all. It's also about the physical effort [...]. You must be active. If you sleep while training, there is less effect. Or maybe there is almost no effect. You need to be active, the muscles must be active' [65].

As this quote suggests, the process of appropriation of the exoskeleton involves a sustained effort not only for the purpose of recapturing damaged motor capacities; what is challenging for users, as well as for the teams of experts accompanying them during the training sessions, is to preserve the acquired progress and hence permanently maintain it within people's stock of body techniques [66]. To actively manufacture temporary abled bodies with exoskeletal devices involves many levels of corporeal co-production in which a variety of regimes of knowledge conflate: that of engineers, the practical field based on physiotherapy, and the expertise each impaired person 
has of herself as an 'insider' (see p. 10 in [5]). All of these regimes of knowledge are necessary in the process of turning disabled people into contextually and sequentially able ones; similarly, they are all critical in forging further boundaries within the field and reorienting the understanding of medical technologies and the possibilities they currently provide.

\section{Conclusion}

Corporeal realities in medical environments are becoming more and more complex, and the research and development of exoskeletons participate in these changes. As such, they influence the way we perceive the reality of our bodies and, as the previously analyzed medical examples show, the vulnerabilities caused by severe impairments. As new technological possibilities of corporeal extension [67, 68], exoskeletons influence our understanding of how we delegate capabilities to machines and of how we redistribute them when they are missing from our 'natural' bodies. Whereas more generally, 'the extension of any sense alters the way we think and act - the way we perceive the world' (see p. 26 in [69]), the changes in motility dispositions related to such examples as spinal cord injury and stroke and operated by exoskeletons exceed the more global register of tool use or mere technological assistance. This happens partly due to the exceptionality of the conditions under which this type of human-machine interaction takes place, and which is by no means conceived in binary terms.

The challenge these new technologies raise follows from the fact that, while they forge new conceptions of what our bodies can or cannot do, they impact the tension between the visibility and invisibility of some forms of impairment on a larger scale. One's being temporarily abled configures simultaneously the conflicts inherent in these processes and the possibilities they concretely open. Changes in motor intentionality as those performed with exoskeletons are without precedent in the history of medical technologies.

The analysis of such an example shows that for a short interval bodies which 'cannot' are allowed to 'be able' again. In highlighting the possibilities of what shapes in/ability, my intention was to contribute to current debates in the broader field of disability studies, as well as to that of the phenomenology of illness and disability. The transition operated by this novel technological gadget recasts the understanding of new forms of corporeal dispositions in terms of possibility, while pointing out how in spite of having lived serious injuries, human bodies reinvent themselves in an ongoing process and with them their phenomenologies. They may thus further deepen our understanding of what one 'can' circumstantially do despite one's 'cannot', while influencing more broadly how we rethink the boundaries between our bodies and medical technologies.

Funding Open Access funding enabled and organized by Projekt DEAL. The research for this article was financially supported by the German Research Council (Deutsche Forschungsgemeinschaft), under the form of a joint funding: the Research Training Group 1767 'Factual and Fictional Narration' (AlbertLudwigs-Universität Freiburg) and the project 'Deviant Bodies. Extended Bodies' BU 3417/2 -1s (University of Konstanz).

Open Access This article is licensed under a Creative Commons Attribution 4.0 International License, which permits use, sharing, adaptation, distribution and reproduction in any medium or format, as long as you give appropriate credit to the original author(s) and the source, provide a link to the Creative Commons licence, and indicate if changes were made. The images or other third party material in this article are included in the article's Creative Commons licence, unless indicated otherwise in a credit line to the material. If material is not included in the article's Creative Commons licence and your intended use is not permitted by statutory regulation or exceeds the permitted use, you will need to obtain permission directly from the copyright holder. To view a copy of this licence, visit http://creativecommons.org/licenses/by/4.0/.

\section{References}

1. Dolezal L (2020) Disability as malleability. The prosthetic metaphor, Merleau-Ponty and the case of Aimee Mullins. In: Butnaru D (ed) Medical bodies between fiction and faction: reinventing corporeality. Transcript, Bielefeld, 2020

2. Smith M, Morra J (eds) (2006) The prosthetic impulse: From a posthuman present to a biocultural future. The MIT Press, Cambridge MA

3. Sobchack V (2016) A leg to stand on: Prosthetics, metaphor, and materiality. Smith $\mathrm{M}$ and Morra $\mathrm{J}$ The prosthetic impulse: From a posthuman present to a biocultural future. The MIT Press, Cambridge MA and London, pp 17-41

4. Carel H (2013) Illness: The cry of the flesh. Routledge, London

5. Carel H (2016) Phenomenology of illness. Oxford University Press, Oxford

6. Svenaeus (2015) The phenomenology of chronic pain: Embodiment and alienation. Cont Philos Rev 48:107-122. https://doi.org/10.1007/s11007-015-9325-5 
7. Gallagher S (2012) Phenomenology. Palgrave Macmillan, Basingstoke

8. Gallagher S (2017) Enactivist interventions. Oxford University Press, Oxford

9. Gallagher S, Zahavi D (2008) The phenomenological mind. Routledge, New York and London

10. Durt C, Fuchs T, Tewes C (2017) Embodiment, enaction and culture: Investigating the constitution of the shared world. The MIT Press, Cambridge MA and London

11. Montero B (2016) Thought in action. Oxford University Press, Oxford

12. Black D (2016) Embodiment and mechanization. Reciprocal understandings of body and machine from the Renaissance to the present. Routledge, London and New York

13. Coeckelbergh M (2017) New romantic cyborgs. Romanticism, information technology, and the end of the machine. The MIT Press, Cambridge MA and London

14. Voskuhl A (2013) Androids in the enlightenment: Mechanics, artisans, and cultures of the self. University of Chicago Press, Chicago

15. Reiser SJ (2009) Technological medicine: The changing world of doctors and patients. Cambridge University Press, Cambridge

16. Conrad P (2005) The shifting engines of medicalization. J Health Soc Behav 46(1):3-14

17. Conrad P (2007) The medicalization of society. The Johns Hopkins University Press, Baltimore

18. Wehling P et al (2007) Zwischen Biologisierung des Sozialen und neuer Biosozialität: Dynamiken der biopolitischen Grenzüberschreitung. Berl J Soziol 17(4):547-567

19. Blume S (1992) Insight and industry. On the dynamics of technological change in medicine. MIT Press, Cambridge Mass, London

20. Schillmeier M (2010) Rethinking disability. Bodies, senses and things. Routledge, New York \& London

21. Tamari T (2017) Body image and prosthetic aesthetics: Disability, technology and Paralympic culture. Body Soc 23(2):25-56. https://doi.org/10.1177/1357034X17697364

22. Crawford S (2014) Phantom limb: Amputation, embodiment, and prosthetic technology. New York University Press, New York

23. Westermann B (2012) Anthropomorphe Maschinen. Grenzgänge zwischen Biologie und Technik seit dem 18. Jahrhundert. Wilhelm Fink Verlag, Paderborn

24. Serlin D (2004) Replaceable you: Engineering the body in Postwar America. University of Chicago Press, Chicago

25. Roeder G Jr (1993) The censored war: American visual experience during World War Two. Yale University Press, New Haven, Conn

26. Perry HR (2002) Re-arming the disabled veteran: Artificiality rebuilding state and society in World War One Germany. In: Serlin DH, Mihm S, Ott K (eds) Artificial parts, practical lives. New York University Press, New York, pp 75-101

27. Perry HR (2005) Brave old world. Recycling der Kriegeskrüppel während des Ersten Weltkrieges. In: Orland B (ed) Artifizielle Körper - Lebendige Technik technische Modellierungen des Körpers in historischer Perspektive. Chronos Verlag, Zürich, pp 147-158

28. Rabier C (2013) Introduction to the special issue: Fitting for health. The crafting of medicine in the early industrial age. Technol Cult 54(3):437-459. https://doi.org/10.1353/ tech.2013.0090
29. Wioland L, Debay L, Atain-Kouadio JJ (2019) Acceptation des exosquelettes par les opérateurs : étude exploratoire. Références en santé au travail $\mathrm{N}^{\circ} 157$ Mars 45-61. http:// www.rst-sante-travail.fr/rst/pages-article/ArticleRST.html? ref=RST.TF\%20264

30. Veneman J (2019) Research - medical exoskeletons. Paper presented at WearRAcon Europe, Fraunhofer Institute for Manufacturing Engineering and Automation IPA, Stuttgart, 19 November 2019

31. Kazerooni H (1990) Human-robot interaction via the transfer of power and information signals. IEEE Transactions on Systems, Man, and Cybernetics 20(2):450463. https://doi.org/10.1109/21.52555

32. Pons JL, Ceres R, Calderon L (2008) Introduction to wearable robotics. In: Pons JL (ed) Wearable robots: Biomechatronic exoskeletons. John Wiley \& Sons, Chichester, pp 1-16

33. Theurel J, Desbrosses K, Roux T, Savescu A (2018) Physiological consequences of using an upper limb exoskeleton during manual handling tasks. Appl Ergon (67):211-217. https://doi.org/10.1016/j.apergo.2017.10.008

34. Black D (2014) Where bodies end and artefacts begin: tools, machines and interfaces. Body Soc 20(1):31-60, p. 38. https://doi.org/10.1177/1357034X13506946

35. Merleau-Ponty M (2012) Phenomenology of perception. Routledge, New York and London

36. Crary J (1990) Techniques of the observer. On vision and modernity in the nineteenth century. The MIT Press, Cambridge MA and London

37. Marx K (1980) Marx’s Grundrisse. Harper and Row Publishers, New York, Hagerstown, San Francisco and London

38. Blume S (1999) Histories of cochlear implantation. Soc Sci Med 49(9):1257-1268. https://doi.org/10.1016/S02779536(99)00164-1

39. Pinch T (2016) Afterword. In: Hyysalo S, Jensen TE, Oudshoorn N (eds.) The new production of users. Changing innovation collectives and involvement strategies. Routledge, New York and London, pp. 325-334

40. Malafouris L (2013) How things shape the mind. The MIT Press, Cambridge Mass., London England

41. Husserl E (1989) Ideas pertaining to a pure phenomenology and to a phenomenological philosophy. Second book. Kluwer, Dordrecht

42. Kyselo M, Di Paolo E (2015) Locked-in syndrome: A challenge for embodied cognitive science. Phenom Cogn Sci 14:517-542. https://doi.org/10.1007/s11097-013-9344-9

43. Zahavi D (2019) Locked-in syndrome: A challenge to standard accounts of selfhood and personhood? Neuroethics. https://doi.org/10.1007/s12152-019-09405-8

44. Gapenne O, Stewart J, Di Paolo E (2014) Enaction: Toward a new paradigm for the cognitive science. The MIT Press, Cambridge MA and London

45. Pickstone J V (ed.) (1992) Medical innovations in historical perspective. Palgrave, Basingstoke

46. Pickstone JV (2001) Ways of knowing: A new history of science, technology, and medicine. University of Chicago Press, Chicago

47. Timmerman C, Anderson J (eds.) Devices and designs: medical technologies in historical perspective. Palgrave, Basingstoke

48. Moser I (2006) Disability and the promises of technology: technology, subjectivity and embodiment within an order of 
the normal. Inf Commun Soc 9(3):373-395, p. 383. https://doi. org/10.1080/13691180600751348

49. Svenaeus F (2018) Phenomenological bioethics. Routledge, London and New York

50. Svenaeus F (2009) The phenomenology of falling ill. An explication, critique and improvement of Sartre's theory of embodiment and alienation. Hum Stud 32:53-66. https://doi.org/10.1007/s10746-009-9109-1

51. Svenaeus F (2011) Illness as unhomelike being-in-theworld: Heidegger and the phenomenology of medicine. Med Health Care and Philos 14:333-343. https://doi.org/ 10.1007/s11019-010-9301-0

52. Murphy R (1990) The body silent. W.W. Norton, New York and London

53. Ott K (2014) Disability things: Material culture and American disability history. In: Burch S, Rembis M (eds) Disability histories. University of Illinois Press, Urbana, Chicago and Springfield, pp 119-135

54. Dalibert L, Goffette J (2020) Qu'est-ce qu'une prothèse ? - Concepts et usages. In : Groud PF, Gourinat V, Jarassé $\mathrm{N}$ (dir.) Corps et prothèses. Presses universitaires de Grenoble, Grenoble, pp. 27-42

55. Oudshoorn N (2015) Sustaining cyborgs: Sensing and tuning agencies of pacemakers and implantable cardioverter defibrillators. Soc Stud Sci 45(1):56-76. https://doi. org/10.1177/0306312714557377

56. Lupton D (2018) Digital health. Critical and cross-disciplinary perspectives. Routledge, London and New York

57. Leder D (1990) The absent body. Chicago University Press, Chicago

58. Droulez T (2011) Usages des bio et neuro-technologies, et conditions de la constitution d'un être singulier, conscient et autonome. In Le Dref G, Droulez T, Allamel-Raffin C (eds). Les usages du vivant. Néothèque, Strasbourg, pp. 223-238

59. Cockelbergh M (2019) Moved by machines. Routledge, New York and London
60. Campbell F (2009) Contours of ableism: the production of disability and abledness. Palgrave, Basingstoke

61. Campbell F (2019) Precision ableism: A studies in ableism approach to developing histories of disability and abledment. Rethink Hist. https://doi.org/10.1080/13642529. 2019.1607475

62. Campbell F Ability. In: Adams R, Reiss B, and Serlin D (eds.) Keywords for disability studies, New York University Press, New York and London, pp. 46-51

63. Gallagher S (2005) How the body shapes the mind. Oxford University Press, Oxford

64. Heersmink R (2013) Embodied tools, cognitive tools and brain-computer interfaces. Neuroethics 6(207-219):213. https://doi.org/10.1007/s12152-011-9136-2:213

65. Riener R (2017) Walking and its rehabilitation. Brain links-brain tools lecture, Universitätsklinikum Freiburg on 12 July 2017

66. Mauss M (1973) Techniques of the body. Econ Soc 2(1):70-88. https://doi.org/10.1080/03085147300000003

67. Fuchs T, Froese T (2012) The extended body: A case study in the neurophenomenology of social interaction. Phenom Cogn Sci 11:205-235. https://doi.org/10.1007/ s11097-012-9254-2

68. Shildrick M (2017) Border crossings. The technologies of disability and desire. In: Waldschmidt A, Berressem $\mathrm{H}$, Ingwersen M (eds.) Culture - Theory - Disability. Encounters between disability studies and cultural studies. Transcript, Bielefeld, pp. 137-169

69. McLuhan M, Fiore Q (1967) The medium is the massage: An inventory of effects. Bantam, New York

Publisher's Note Springer Nature remains neutral with regard to jurisdictional claims in published maps and institutional affiliations. 